\title{
Analisa Pengaruh Penggunaan Gadget Terhadap Nilai Akhir Siswa SMA Secara Umum Menggunakan Metode Data mining (Decision Tree)
}

\author{
Raja Alveraldo Simarmata*1, Yusran Timur Tarihoran² \\ 1,2 Fakultas Teknologi Informasi, Universitas Advent Indonesia \\ e-mail: *11782001@unai.edu, 2y.tarihoran@unai.edu
}

\begin{abstract}
Abstrak
Ramainya penggunaan gadget saat ini sudah mengisi kehidupan setiap individu termasuk remaja. Di masa ini, jarang sekali melihat remaja yang pergi ke mana saja tanpa membawa gadget. Salah satu contoh gadget yang paling mudah untuk dibawa adalah handphone. Dengan ramainya populasi gadget pada remaja, tentunya akan memberikan pengaruh baik juga buruk kepada sikap belajar dan juga nilai mereka disekolah. Tujuan dari penelitian adalah untuk mengetahui apakah ada pengaruh dari penggunaan gadget pada nilai akhir anak-anak murid SMA secara umum tanpa tertuju pada satu sekolah saja. Metode yang digunakan dalam penelitian ini adalah metode data mining dengan algoritma id3 decision tree. Hasil dari penelitian ini ialah bahwa penggunaan gadget tidak mempengaruhi nilai akhir dari siswa SMA secara umum.
\end{abstract}

Kata Kunci: Gadget, Data Mining, ID3, Siswa SMA

\section{Analysis of the Effect of Gadget Use on the Final Score of High School Students in General Using the Data mining Method \\ (Decision Tree)}

\begin{abstract}
The hectic use of gadgets has filled the lives of every individual, including teenagers. At this time, it is rare to see teenagers who go anywhere without carrying gadgets. One example of a gadget that is easiest to carry is a cellphone. With the hectic population of gadgets in adolescents, of course it will have a good or bad influence on their learning attitudes and also their grades in school. The purpose of this study was to determine whether there is an effect of the use of gadgets on the final grades of high school students in general without focusing on just one school. The method used in this research is data mining method with ID3 decision tree algorithm. The result of this study is that the use of gadgets does not affect the final grades of high school students in general.
\end{abstract}

Keywords: Gadgets, Data Mining, ID3, High School Students

\section{Pendahuluan}

Pada era serba teknologi pada saat ini, tidak dapat dipungkiri bahwa penggunaan gadget sehari-hari semakin pesat. Saat ini, gadget sudah menjadi genggaman sehari-hari di semua kalangan usia dari muda sampai tua. Hampir semua bidang termasuk pendidikan melibatkan gadget dalam kegiatannya. Di masa pandemik seperti ini, penggunaan gadget pada anak sekolah pun semakin intens karena kegiatan belajar yang diadakan secara daring. Dengan adanya teknologi yang terus berkembang, konten-konten yang di akses pun semakin banyak juga semakin banyak pula pengaruh dari konten-konten tersebut untuk para pengguna gadget. Mengambil contoh mudah seperti penggunaan Handphone. Konten yang dapat diakses 
dari handphone tidak ada habisnya seperti penggunaan untuk media sosial, hiburan, dan juga Pendidikan. Penggunaan setiap individu tentunya berbeda dan konten yang diakses pun berbeda, bahkan intensitas penggunaannya pun berbeda. Oleh karena itu, penggunaan gadget terhadap sikap belajar dan pada hasil nilai akhir pasti memiliki pengaruh baik itu pengaruh baik atau buruk.

Gadget istilah dalam Bahasa inggris yang artinya adalah alat elektronik kecil yang memiliki banyak kegunaan. Gadget secara umum memiliki beberapa fungsi yang praktis. Gadget juga memiliki beberapa fungsi dan manfaat yang relatif bagi penggunanya seperti komunikasi, sosial, dan Pendidikan [1].

Data mining adalah sebuah proses mencari informasi dari sebuah kumpulan data yang berupa pengetahuan yang tidak dapat diketahui tanpa bantuan proses data mining [2]. Data mining adalah sebuah bidang keilmuan yang memanfaatkan teknik pembelajaran mesin, pengenalan pola, statistik, database, dan visualisasi untuk menangani masalah pengambilan informasi dari data yang besar. Data mining akan mengolah data mentah yang tersimpan dalam database hingga memberikan informasi penting. Data mentah adalah data yang disimpan untuk bagian dokumentasi. Pengolahan data mentah dimanfaatkan untuk membuat laporan, mengendalikan kebutuhan, mencari informasi dan pengetahuan yang baru. Data mining menelusuri data dari database untuk membangun model dan memanfaatkannya agar mengenali pola data lain yang tidak tersimpan dalam basis data.

Pada penelitian ini, penulis membatasi responden yaitu murid murid SMA kelas 1-3 namun dari beberapa sekolah secara random. Pengambilan sampel dilakukan dengan cara mengisi kuesioner online yang sudah disebar juga secara acak. Penelitian ini dikhususkan penulis untuk mencari tahu apa pengaruh penggunaan gadget pada siswa SMA terhadap nilai-nilai akhir mereka. Tujuan dari penelitian ini adalah untuk mengetahui apa pengaruh penggunaan gadget pada siswa SMA kepada nilai akhir siswa.

\section{Tinjauan Pustaka dan Landasan Teori}

\section{Tinjauan Pustaka}

Penulis sudah mengkaji beberapa topik yang berkaitan dengan pengaruh penggunaan gadget terhadap nilai akhir siswa di antaranya sebagai berikut.

Penelitian yang berjudul "Pengaruh Penggunaan Gadget Terhadap Prestasi Dan Hasil Belajar Siswa Sekolah Dasar". Tujuan dari penelitian ini adalah untuk mengetahui pengaruh penggunaan gadget pada prestasi dan hasil belajar pada siswa. Penelitian ini dijalankan pada siswa SD kelas 5 di salah SD di kota Salatiga. Metode yang digunakan dalam penelitian ini adalah metode kuantitatif. Teknik yang digunakan dalam mengambil sampel menggunakan teknik Stratified Sampling. Hasil dari penelitian tersebut adalah siswa kelas 5 di SD tersebut tidak memiliki ketergantungan pada gadget. Dilihat dari hasil pengolahan kuesioner yang sudah diberikan dan juga hasil rekapan nilai rapor semester genap mereka [3].

Selain penelitian itu, ada penelitian yang berjudul "Pengaruh Penggunaan Gadget Terhadap Tingkat Prestasi Siswa SMPN Satu Atap Pakis Jaya Karawang". Dari hasil penelitian tersebut, dapat disimpulkan bahwa semakin tinggi penggunaan gadget maka akan berpengaruh pada tingkat konsentrasi belajar yang akan mempengaruhi nilai dan tingkat prestasi siswa [4].

Persamaan dari kedua penelitian ini adalah keduanya meneliti mengenai pengaruh penggunaan gadget terhadap nilai dan tingkat prestasi siswa di sekolah dan juga keduanya tidak ada yang menggunakan metode data mining. Perbedaan dari kedua penelitian ini terletak pada subyek yang diteliti dimana salah satu penelitian tersebut dijalankan di tingkat SD dan penelitian yang lainnya dilakukan di tingkat SMPN. Sedangkan di penelitian ini dilakukan kepada tingkat SMA. 


\section{Landasan Teori}

\section{Data Mining}

Data mining adalah proses penggalian data yang menggunakan kumpulan data yang jumlahnya besar melalui sebuah proses untuk mencari informasi penting dari data tersebut [5].

\section{Decision Tree}

Decision tree adalah sebuah struktur flowchart yang mirip dengan Tree (pohon), yang setiap simpul internal menandakan suatu tes pada atribut, tiap cabangnya merepresentasikan hasil tes, dan simpul daun menandakan kelas atau distribusi kelas [2]. Alur daripada Decision tree di lihat dari simpul akar ke simpul daun yang memegang prediksi.

Menurut Jamal Situmeang dalam penelitiannya menyebutkan bahwa data mining dan Knowledge Discovery in Database (KDD) sering dipakai secara bergantian dalam sebuah proses mencari informasi tersembunyi dari suatu database yang besar. Data mining merupakan salah satu tahapan dari keseluruhan proses KDD [6].

\section{Decision Tree ID3}

Pada tahun 1986, J.Rose mengembangkan sebuah metode pohon keputusan yang lebih baik yaitu Iterative Dichotomiser3 (ID3). Algoritma dari ID3 ini adalah menggunakan konsep entropi informasi. Algoritma ini akan melakukan pencarian secara menyeluruh untuk seluruh kemungkinan dari pohon keputusan.

Langkah kerja dari Algoritma ID3 digambarkan sebagai berikut:

1. Menghitung Entropi dan informasi gain dari setiap atribut dengan menggunakan rumus:

Dimana:

$$
\operatorname{Entropy}(S)=-P_{+} \log _{2} P_{+}-P_{-} \log _{2} P_{-}
$$

$\mathrm{S}=$ Ruang (data) sampel yang digunakan.

$\mathrm{P}+=$ Jumlah yang positif (mendukung) dari sebuah sampel data dengan ketentuan tertentu.

$\mathrm{P}$ - = Jumlah yang negatif (tidak mendukung) dari sebuah sampel data dengan ketentuan tertentu.

$$
\operatorname{Gain}(S, A)=\operatorname{Entropy}(S)-\sum_{\operatorname{nilai}(A)} \frac{\left|S_{v}\right|}{|S|} \operatorname{Entropy}\left(S_{v}\right)
$$

Dimana:

$S=$ Ruang (Data) sampel yang digunakan untuk training

$A=$ Atribut.

$\mathrm{V}=$ Suatu nilai yang memungkinkan untuk atribut $A$.

$\operatorname{Nilai}(A)=$ Suatu himpunan yang memungkinkan untuk atribut $A$.

ISvI = Jumlah sampel untuk nilai $\mathrm{V}$.

ISI = Jumlah seluruh sample data.

Entropy (Sv) = Entropi untuk sampel-sampel yang memiliki nilai V.

Maksud dari pengukuran nilai informasi gain ini adalah untuk memilih atribut yang akan dijadikan cabang pada pembentukan decision tree.

2. Membuat simpul yang berisi atribut tersebut.

3. Ulang proses perhitungan informasi gain yang akan terus dilakukan hingga semua data telah masuk ke dalam kelas yang sama. Atribut yang sudah dipilih tidak akan diikutkan kembali dalam perhitungan nilai gain. 
ID3 akan berhenti apabila atribut telah sempurna mengklasifikasikan training sets, atau secara rekursif mengoperasikan nilai $\mathrm{n}$, yang dimana $\mathrm{n}$ adalah banyaknya nilai kemungkinan dari sesuatu untuk mendapatkan atribut paling baik.

Sampel data yang digunakan oleh ID3 memiliki beberapa syarat, yaitu:

- Deskripsi atribut-nilai. Atribut yang sama harus mendeskripsikan setiap contoh dan memiliki jumlah nilai yang ditentukan.

- Kelas yang telah didefinisikan sebelumnya. Atribut contoh sudah harus didefinisikan, karena mereka belum dipelajari oleh ID3.

- Kelas-kelas yang disktrit. Kelas harus digambarkan dengan jelas. Kelas yang kontinu akan dipecah menjadi beberapa kategori yang relatif.

- Jumlah example yang cukup. Oleh karena pembangkitan induktif yang digunakan, maka dibutuhkan sebuah test case yang cukup untuk membedakan pola yang valid dari peluang sebuah kejadian.

\section{Pre Pruning}

Pre Pruning adalah memberhentikan pembangunan sebuah sub-tree lebih cepat dengan cara menghentikan untuk tidak mempartisi data training lebih jauh lagi. Berikut adalah rumus Pre pruning:

$$
e=\frac{r+\frac{Z^{2}}{2 n} \sqrt{\frac{r}{n}-\frac{r^{2}}{n}-\frac{Z^{2}}{4 n^{2}}}}{1+\frac{Z^{2}}{n}}
$$

\section{Dimana:}

$r=$ nilai perbandingan error rate

$\mathrm{n}=$ total sampel

$\mathrm{z}=\Phi-1(\mathrm{c})$

\section{RapidMiner}

RapidMiner adalah sebuah software yang berguna untuk mengolah data dengan prinsip data mining. RapidMiner mengambil pola dari data set yang ada kemudian menggunakan metode statistika, kecerdasan dan database. RapidMiner memudahkan pengguna untuk mengolah data dengan menggunakan operatoroperator yang ada. Operator tersebut akan disambungkan dan dijadikan satu dengan node kemudian menyajikan hasilnya secara grafik visual [7].

\section{Metode Penelitian}

\section{Populasi dan Subjek Penelitian}

Populasi adalah daerah atau wilayah yang terdiri dari: obyek atau subyek yang memiliki karakter dan kualitas yang telah ditetapkan oleh peneliti untuk ditarik kesimpulan nantinya [3]. Populasi yang dipilih oleh penulis dalam penelitian ini adalah murid SMA kelas 1-3 secara umum dari berbagai macam sekolah dan dari daerah mana saja kuesioner ini disebar.

\section{Teknik Pengumpulan Data}

Teknik pengumpulan data yang digunakan oleh penulis dalam penelitian ini adalah dengan menyebarkan kuesioner. Kuesioner ini disebar melalui kerabat terdekat yang berada di jenjang pendidikan 
SMA. Kuesioner yang telah disiapkan oleh penulis sudah dalam bentuk google form agar dapat disebar dengan mudah.

\section{Desain Penelitian}

Penelitian ini dilakukan dengan studi Pustaka, Analisa, lalu mencari data siswa SMA, yaitu data yang dikumpulkan selama penelitian mengenai fakta dan objek yang diteliti. Subyek yang diteliti adalah siswa SMA secara umum. Responden akan mengisi kuesioner online yang telah di share dan akan mengisi kuesioner berdasarkan atribut yang didapatkan. Data responden kemudian akan diolah menggunakan aplikasi RapidMiner menggunakan metode Decision tree untuk mengimplementasi algoritma ID3 pada program data mining.

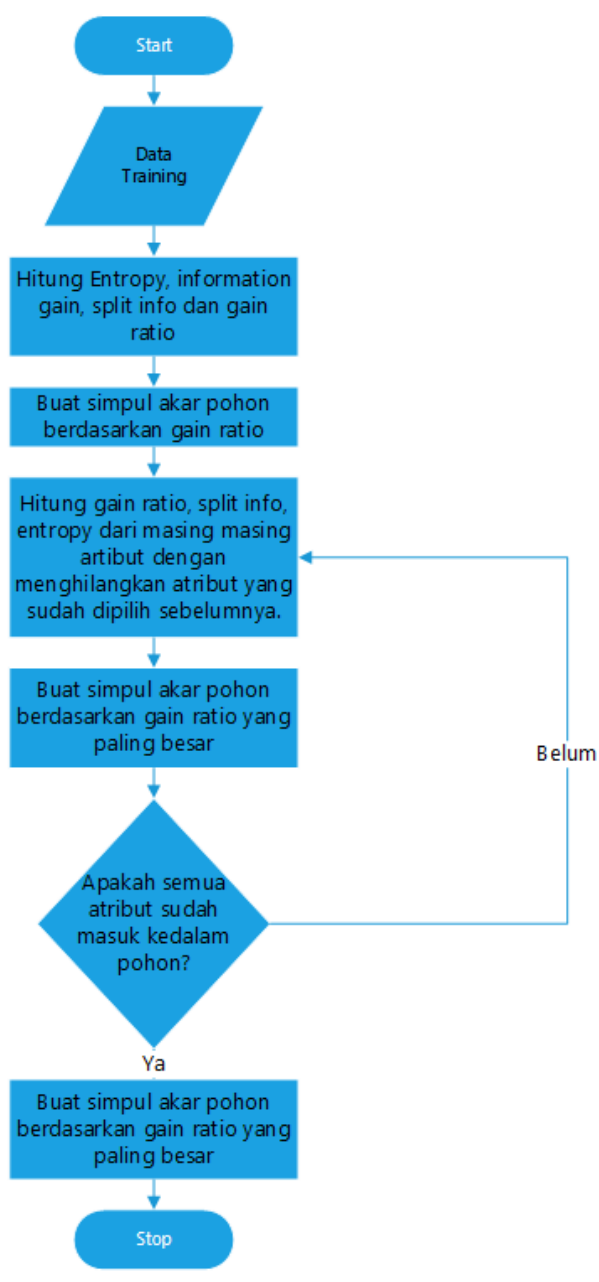

Gambar 1 Flowchart pohon keputusan

\section{Menetapkan Atribut}

Data diperoleh menggunakan kuesioner yang dibagikan secara online menggunakan Google Form dan disebarkan secara acak kepada anak-anak SMA melalui relasi dan dimulai pada tanggal 2 Februari 2020 sampai dengan tanggal 3 Maret 2020. Pertanyaan dalam kuesioner yang diberikan berjumlah 6 pertanyaan. Beberapa dari pertanyaan tersebut akan dipilih untuk menjadi atribut input. 
Tabel 1 Pertanyaan dalam kuesioner

\begin{tabular}{|l|l|}
\hline No & Pertanyaan \\
\hline 1 & Jenis Kelamin \\
\hline 2 & Apakah Anda Mengikuti Ekstrakurikuler? \\
\hline 3 & Rata-rata Waktu Luang Dalam Sehari \\
\hline 4 & Rata-rata Waktu Menggunakan Gadget Dalam Sehari \\
\hline 5 & Jurusan Yang Diambil \\
\hline 6 & Nilai Akhir Mata Pelajaran Sesuai Jurusan \\
\hline
\end{tabular}

\section{Cleaning Data}

Penelitian ini menggunakan data siswa SMA secara umum. Dari proses cleaning, maka data yang akan dipakai untuk atribut model decision tree adalah Jenis Kelamin, Mengikuti Ekstrakurikuler atau tidak, Waktu luang dalam sehari, Intensitas penggunaan gadget dalam sehari. Keempat atribut ini akan digunakan sebagai input.

\section{Transformasi Data}

Setelah melalui proses cleaning, maka langkah berikutnya adalah melakukan transformasi data. Berdasarkan data yang sudah didapat, data yang akan ditransformasikan adalah Jenis Kelamin, Mengikuti Ekstrakurikuler, Waktu luang dalam sehari, Waktu menggunakan gadget dalam sehari, Rata-rata dari seluruh nilai akhir mata pelajaran. Data yang sudah dipilih tersebut akan dijadikan atribut input untuk membangun model decision tree. Proses transformasi dilakukan dengan melakukan klasifikasi dari masingmasing atribut input seperti yang diperlihatkan di tabel 2.

Tabel 2 Klasfikasi Atribut Input

\begin{tabular}{|l|l|l|}
\hline No & Atribut & Klas \\
\hline 1 & Jenis Kelamin & Laki-laki \\
\cline { 3 - 3 } & & Perempuan \\
\hline 2 & Mengikuti Ekstrakurikuler & Ya \\
\cline { 3 - 3 } & & Tidak \\
\hline 3 & Waktu Luang dalam sehari & $1-2$ jam \\
\cline { 3 - 3 } & & 3 jam \\
\cline { 3 - 3 } & & 4 jam \\
\cline { 3 - 3 } & & Di atas 5 jam \\
\hline 4 & Waktu menggunakan gadget dalam sehari & Di bawah 3 jam (rendah) \\
\cline { 3 - 4 } & & 3 jam (sedang) \\
\cline { 3 - 4 } & & Di atas 3 jam (tinggi) \\
\hline
\end{tabular}

Pada tabel 2 dijelaskan bahwa keempat atribut tersebut akan digunakan sebagai input dan sudah memiliki klasifikasi masing-masing agar mempermudah proses data mining. Keempat atribut tersebut akan diolah menggunakan algoritma id3 untuk menentukan apakah pengaruh dari penggunaan gadget untuk nilai akhir siswa SMA. Dalam sebuah penelitian yang dilakukan pada murid SMP di sebuah sekolah di Malang, penulis penelitian tersebut menyebutkan bahwa intensitas penggunaan gadget dalam sehari terbagi menjadi tiga, yaitu rendah (di bawah 3 jam sehari), sedang (sekitar 3 jam sehari), dan tinggi (di atas 3 jam sehari) [8].

Tabel 3 Atribut Target

\begin{tabular}{|l|l|}
\hline Atribut Target & Keterangan \\
\hline Sangat Baik & Nilai $>85-100$ \\
\hline Baik & Nilai $>70-85$ \\
\hline Cukup & Nilai $>55-70$ \\
\hline Kurang & Nilai $<55$ \\
\hline
\end{tabular}


Pada website kompas.com menyebutkan bahwa ada 4 kriteria capaian nilai yaitu Sangat Baik (nilai di atas 85), Baik (nilai di atas 70 namun di bawah 85), Cukup (nilai di atas 55 namun di bawah 70), dan Kurang (nilai di bawah 55) [9]. Tabel 3 menjelaskan bahwa terdapat 4 klasifikasi dari atribut target yang diinginkan yaitu Sangat Baik, Baik, Cukup, dan Kurang.

Data yang akan digunakan untuk membangun model decision tree terdiri dari 4 atribut dan 1 atribut target. Untuk pengolahan data akan menggunakan algoritma id3 dan jumlah data yang diolah sebanyak 205 data yang sudah diambil secara acak dari berbagai SMA. Kemudian 205 data tersebut akan ditransformasikan hingga memberikan keputusan (Sangat Baik, Baik, Cukup, Kurang). Berikut adalah contoh dengan data asli sejumlah 10 data yang sudah ditransformasi.

Tabel 4 Contoh Transformasi Data

\begin{tabular}{|c|c|c|c|c|c|}
\hline No & Jenis Kelamin & Ekstrakurikuler & Waktu Luang & $\begin{array}{c}\text { Intensitas Penggunaan } \\
\text { Gadget }\end{array}$ & $\begin{array}{c}\text { Kategori } \\
\text { Nilai }\end{array}$ \\
\hline 1 & Laki-laki & Ya & 4 jam & Tinggi & Sangat Baik \\
\hline 2 & Perempuan & Ya & 4 jam & Rendah & Baik \\
\hline 3 & Laki-laki & Ya & 3 jam & Tinggi & Sangat Baik \\
\hline 4 & Perempuan & Tidak & 3 jam & Tinggi & Baik \\
\hline 5 & Perempuan & Tidak & 4 jam & Tinggi & Sangat Baik \\
\hline 6 & Laki-laki & Ya & 4 jam & Tinggi & Sangat Baik \\
\hline 7 & Perempuan & Tidak & Di atas 5 jam & Sedang & Sangat Baik \\
\hline 8 & Perempuan & Ya & Di atas 5 jam & Tinggi & Baik \\
\hline 9 & Laki-laki & Ya & 3 jam & Sedang & Baik \\
\hline 10 & Laki-laki & Ya & 4 jam & Tinggi & Baik \\
\hline
\end{tabular}

\section{Merancang Decision Tree}

Berdasarkan tabel 4 yang adalah contoh-contoh dari data yang telah ditransformasi, maka akan dilakukan proses perhitungan untuk menentukan akar dari pohon keputusan tersebut. Berikut adalah tabel perhitungan node 1.

Tabel 5 Penentuan node 1

\begin{tabular}{|c|c|c|c|c|c|c|c|}
\hline Node & Atribut & Nilai & $\begin{array}{l}\text { Sum } \\
\text { (Nilai) }\end{array}$ & $\begin{array}{l}\text { Sum } \\
\text { (Baik) }\end{array}$ & $\begin{array}{l}\text { Sum } \\
\text { (S.Baik) }\end{array}$ & Entropi & Gain \\
\hline \multirow[t]{14}{*}{1} & Jenis Kelamin & & & & & & 0.471228762 \\
\hline & & Laki-Laki & 5 & 3 & 2 & 0.970950594 & \\
\hline & & Perempuan & 5 & 2 & 3 & 0.086591881 & \\
\hline & Ekstrakurikuler & & & & & & \\
\hline & & $\mathrm{Ya}$ & 7 & 3 & 4 & 0.985228136 & 0.034851555 \\
\hline & & Tidak & 3 & 1 & 2 & 0.918295834 & \\
\hline & Waktu Luang & & & & & & \\
\hline & & $3 \mathrm{Jam}$ & 3 & 2 & 1 & 0.138345833 & 0.273020953 \\
\hline & & 4 Jam & 5 & 2 & 3 & 0.970950594 & \\
\hline & & $\begin{array}{l}\text { Di atas } 5 \\
\text { Jam }\end{array}$ & 2 & 1 & 1 & 1 & \\
\hline & Intensitas & & & & & & \\
\hline & & Rendah & 1 & 1 & 0 & 0 & 0.110340305 \\
\hline & & Sedang & 2 & $\frac{1}{1}$ & 1 & 1 & \\
\hline & & Tinggi & 7 & 4 & 3 & 0.985228136 & \\
\hline
\end{tabular}

Dari data yang berada di tabel 5 , langkah berikut yang harus dilakukan adalah menghitung Keseluruhan entropi. Setelah mendapatkan entropi dari seluruh kasus, lakukan analisis dari setiap atribut dan nilai nilainya lalu menghitung entropi dan gain dari setiap variabel. 


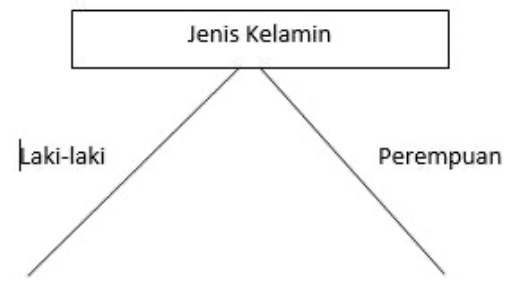

Gambar 2 Node 1

Hasil yang didapat dari node 1 adalah Jenis Kelamin menjadi node akar dikarenakan nilai gainnya terbesar. Berdasarkan pembentukan pohon keputusan node 1, node 2 akan di analisis lebih lanjut. Untuk mempermudah, tabel di bawah difilter, dengan mengambil data yang memiliki Jenis Kelamin = Laki-laki.

Hitung entropi dari Jenis Kelamin laki-laki dan entropi setiap atribut serta gainnya. Setelah itu tentukan gain tertinggi untuk dibuatkan node berikutnya.

Tabel 6 Penentuan Node 2

\begin{tabular}{|l|l|l|l|l|l|l|l|}
\hline Node & Atribut & Nilai & $\begin{array}{l}\text { Sum } \\
\text { (Nilai) }\end{array}$ & $\begin{array}{l}\text { Sum } \\
\text { (Baik) }\end{array}$ & $\begin{array}{l}\text { Sum (Sangat } \\
\text { Baik) }\end{array}$ & Entropi & Gain \\
\hline 1.2 & Ekstrakurikuler & & & & & & \\
\hline & & Ya & 5 & 2 & 3 & 0.970950594 & \\
\hline & & Tidak & 0 & 0 & 0 & 0 & \\
\hline & Waktu Luang & & & & & & 0.938268928 \\
\hline & & 3 Jam & 2 & 1 & 1 & 1 & \\
\hline & & 4 Jam & 3 & 2 & 1 & 0.918295834 & \\
\hline & $\begin{array}{l}\text { Di atas 5 } \\
\text { Jam }\end{array}$ & 0 & 0 & 0 & 0 & \\
\hline & $\begin{array}{l}\text { Intensitas } \\
\text { penggunaan } \\
\text { gadget }\end{array}$ & & & & & & 0.321928095 \\
\hline & & Rendah & 0 & 0 & 0 & 0 & \\
\hline & & Sedang & 1 & 1 & 0 & 0 & \\
\hline & & Tinggi & 4 & 3 & 1 & 0.811278124 & \\
\hline
\end{tabular}

Gain tertinggi yang di dapat adalah atribut Waktu Luang, dan nilai yang dijadikan daun adalah 3 Jam dan 4 Jam. Setelah di evaluasi maka pohon keputusan tampak seperti gambar di bawah.

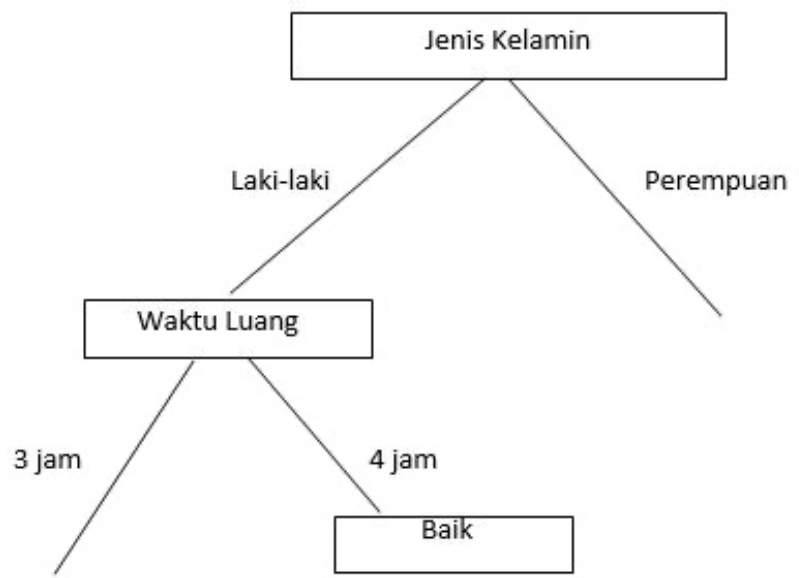

Gambar 3 Node 2 
Untuk menganalisis node 1.2.2 lakukan lagi langkah langkah yang sama seperti sebelumnya.

Tabel 7 Penentuan Node 3

\begin{tabular}{|c|c|c|c|c|c|c|c|}
\hline Node & Atribut & Nilai & Sum (Nilai) & Sum (Baik) & $\begin{array}{l}\text { Sum (Sangat } \\
\text { Baik) }\end{array}$ & Entropi & Gain \\
\hline \multirow[t]{7}{*}{1.2 .2} & Ekstrakurikuler & & & & & & 0 \\
\hline & & Ya & 2 & 1 & 1 & 1 & \\
\hline & & Tidak & 0 & 0 & 0 & 0 & \\
\hline & $\begin{array}{l}\text { Intensitas } \\
\text { penggunaan } \\
\text { gadget }\end{array}$ & & & & & & 1 \\
\hline & & Rendah & 0 & 0 & 0 & 0 & \\
\hline & & Sedang & 1 & 1 & 0 & 0 & \\
\hline & & Tinggi & 1 & 0 & 1 & 0 & \\
\hline
\end{tabular}

Dari seluruh proses di atas, di bawah ini adalah bentuk dari pohon perhitungan seluruh node yang sudah berbentuk leaf.

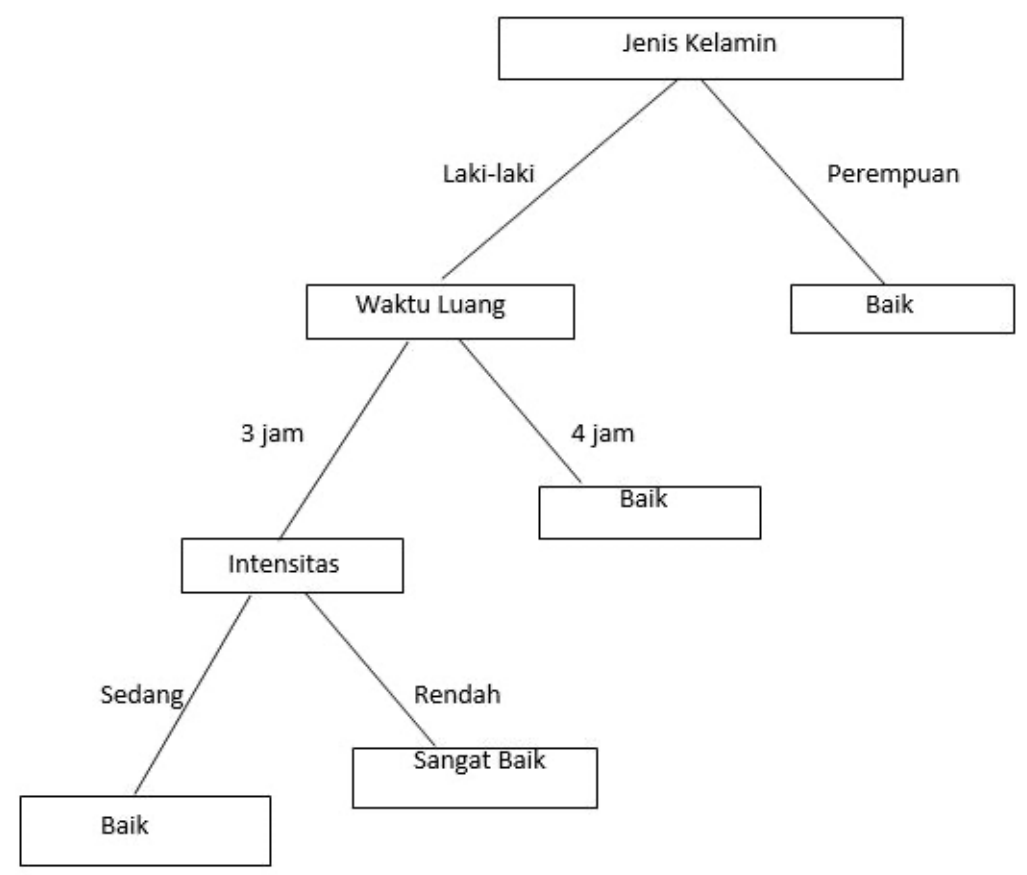

Gambar 4 Node 3

\section{Hasil dan Pembahasan}

\section{Hasil Pengujian Data}

Dari hasil pengujian data, tentu akan ada hasil dari confusion matrix juga. Berikut adalah rumus dalam perhitungan pada confusion matrix.

Keterangan:

1. True Positive (TP): proporsi positif pada dataset yang diklasifikasi positif.

2. True Negative (FN): proporsi negatif pada dataset yang diklasifikasi negatif. 
3. False Positive (FP): proporsi negatif pada dataset yang diklasifikasi positif.

4. False Negative (TN): proporsi positif pada dataset yang diklasifikasi negatif.

Rumus perhitungan recall:

$$
\text { Recall }=\frac{T P}{T P+F N}
$$

Rumus perhitungan precision:

$$
\text { Precision }=\frac{T P}{T P+F P}
$$

Rumus perhitungan akurasi:

$$
\text { Accuracy }=\frac{a+d}{a+b+c+d}=\frac{T P+T N}{T P+T N+F P+F N}
$$

\begin{tabular}{|c|c|c|c|c|c|}
\hline & true Baik & true Sangat Baik & true Cukup & true Kurang & class precision \\
\hline pred. Baik & 49 & 37 & 2 & 3 & $53.85 \%$ \\
\hline pred. Sangat Baik & 35 & 31 & 2 & 3 & $43.66 \%$ \\
\hline pred. Cukup & 0 & 0 & 0 & 0 & $0.00 \%$ \\
\hline pred. Kurang & 0 & 1 & 0 & 1 & $50.00 \%$ \\
\hline class recall & $58.33 \%$ & $44.93 \%$ & $0.00 \%$ & $14.29 \%$ & \\
\hline
\end{tabular}

Hasil dari data yang telah di uji menjelaskan bahwa akurasi yang ditunjukkan oleh tabel berikut memiliki tingkat akurasi di 49,39\%.

Gambar 5 Hasil Pengujian Data

Dari gambar hasil pengujian di atas, dapat dijelaskan sebagai berikut:

a. 49 data prediksi baik diklasifikasikan sebagai baik. 37 data prediksi baik diklasifikasikan sebagai sangat baik. 2 data prediksi baik diklasifikasikan sebagai cukup. 3 data prediksi baik diklasifikasikan sebagai kurang.

b. 35 data prediksi sangat baik diklasifikasikan sebagai baik, 31 data prediksi sangat baik diklasifikasikan sebagai sangat baik, 2 data prediksi sangat baik diklasifikasikan sebagai cukup, 3 data prediksi sangat baik diklasifikasikan sebagai kurang.

c. 0 data prediksi cukup diklasifikasikan sebagai baik, 0 data prediksi cukup diklasifikasikan sebagai sangat baik, 0 data prediksi cukup diklasifikasikan sebagai cukup, 0 data prediksi cukup diklasifikasikan sebagai kurang.

d. 0 data prediksi kurang diklasifikasikan sebagai baik, 1 data prediksi kurang diklasifikasikan sebagai sangat baik, 0 data prediksi kurang diklasifikasikan sebagai cukup, 1 data prediksi kurang diklasifikasikan sebagai data kurang.

Untuk penjelasan class precission dan class recal/ dijelaskan sebagai berikut:

a. Precision dari data prediksi baik adalah $53,85 \%$ yang dikalkulasikan dari 49 data prediksi baik dibagi dengan 84 data yang diklasifikasikan baik. Recall berjumlah $58,33 \%$ yang dikalkulasikan dari 49 data prediksi baik dibagi dengan 91 data keseluruhan data prediksi baik.

b. Precision dari data prediksi sangat baik adalah 43,66\% yang dikalkulasikan dari 31 data prediksi sangat baik dibagi dengan 69 data yang diklasifikasikan sangat baik. Recall berjumlah 44,93\% yang dikalkulasikan dari 31 data prediksi sangat baik dibagi dengan 71 data keseluruhan data prediksi sangat baik.

c. Precision dari data prediksi cukup adalah $0,00 \%$ yang dikalkulasikan dari 0 data prediksi cukup dibagi dengan 0 data yang diklasifikasikan cukup. Recall berjumlah $0,00 \%$ yang dikalkulasikan dari 0 data prediksi cukup dibagi dengan 0 data keseluruhan data prediksi cukup. 
d. Precision dari data prediksi kurang adalah 50,00\% yang dikalkulasikan dari 1 data prediksi kurang dibagi dengan 7 data yang diklasifikasikan kurang. Recal/ berjumlah 14,29\% yang dikalkulasikan dari 1 data prediksi kurang dibagi dengan 2 data keseluruhan data prediksi cukup.

\section{Hasil Pohon Keputusan}

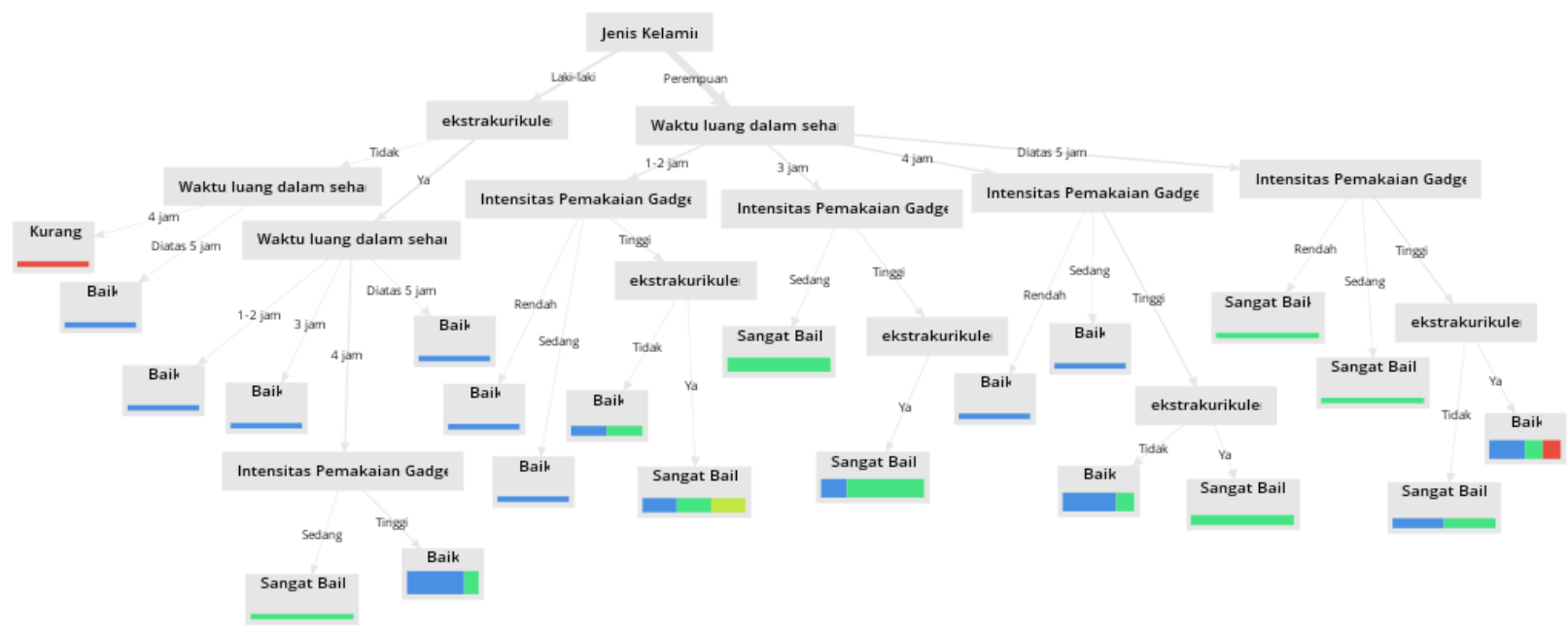

Gambar 3 Hasil Pohon Keputusan

Berdasarkan pengujian yang telah dilakukan, maka dapat disimpulkan bahwa analisis pengaruh penggunaan gadget terhadap nilai akhir siswa SMA secara umum menggunakan metode algoritma ID3 adalah sebagai berikut:

.1 Jenis Kelamin > Laki -laki, tidak, 4 jam, kurang = Kurang

Bila jenis kelamin Laki-laki, tidak mengikuti ekstrakurikuler, waktu luang dalam sehari 4 jam, maka digolongkan sebagai kurang.

2. Jenis Kelamin > Laki-laki, tidak, di atas 5 jam, baik = Baik

Bila jenis kelamin Laki-laki, tidak mengikuti ekstrakurikuler, waktu luang dalam sehari di atas 5 jam, maka digolongkan sebagai baik.

3. Jenis Kelamin > Laki-laki, ya, 1-2 jam, baik = Baik

Bila jenis kelamin Laki-laki mengikuti ekstrakurikuler, waktu luang dalam sehari 1-2 jam, maka digolongkan sebagai baik.

4. Jenis Kelamin > laki-laki, ya, 3 jam, baik = Baik

Bila jenis kelamin Laki-laki, mengikuti ekstrakurikuler, waktu luang dalam sehari 3 jam, maka digolongkan sebagai baik. 
5. Jenis Kelamin > Laki-laki, ya, 4 jam, sedang, sangat baik = Sangat Baik

Bila jenis kelamin Laki-laki, mengikuti ekstrakurikuler, waktu luang dalam sehari 4 jam, intensitas penggunaan gadget sedang, maka digolongkan sebagai sangat baik.

6. Jenis Kelamin > Laki-laki, ya, 4 jam, tinggi, baik = Baik

Bila jenis kelamin Laki-laki, mengikuti ekstrakurikuler, waktu luang dalam sehari 4 jam, intensitas penggunaan gadget tinggi, maka digolongkan sebagai baik.

7. Jenis Kelamin > Laki-laki, ya, di atas 5 jam, baik = Baik

Bila jenis kelamin Laki-laki, mengikuti ekstrakurikuler, waktu luang dalam sehari 5 jam, maka digolongkan sebagai baik.

8. Jenis Kelamin > Perempuan, 1-2 jam, rendah, baik = Baik

Bila jenis kelamin Perempuan, waktu luang dalam sehari 1-2 jam, intensitas penggunaan gadget rendah, maka digolongkan sebagai baik.

9. Jenis Kelamin > Perempuan, 1-2 jam, sedang, baik = Baik

Bila jenis kelamin Perempuan, waktu luang dalam sehari 1-2 jam, intensitas penggunaan gadget sedang, maka digolongkan sebagai baik.

10. Jenis Kelamin > Perempuan, 1-2 jam, tinggi, tidak, baik = Baik

Bila jenis kelamin Perempuan, waktu luang dalam sehari 1-2 jam, intensitas penggunaan gadget tinggi, tidak mengikuti ekstrakurikuler, maka digolongkan sebagai baik.

11. Jenis Kelamin > Perempuan. 1-2 jam. Tinggi, ya, Sangat baik = Sangat Baik

Bila jenis kelamin Perempuan, waktu luang dalam sehari 1-2 jam, intensitas penggunaan gadget tinggi, mengikuti ekstrakurikuler, maka digolongkan sebagai sangat baik.

12. Jenis Kelamin > Perempuan, 3 jam, sedang, sangat baik = Sangat Baik

Bila jenis kelamin Perempuan, waktu luang dalam sehari 3 jam, intensitas penggunaan gadget sedang, maka digolongkan sebagai sangat baik.

13. Jenis Kelamin > Perempuan, 3 jam, tinggi, ya, sangat baik = Sangat Baik

Bila jenis kelamin Perempuan waktu luang dalam sehari 3 jam, intensitas penggunaan gadget tinggi, mengikuti ekstrakurikuler, maka digolongkan sebagai sangat baik. 
14. Jenis Kelamin > Perempuan, 4 jam, rendah, baik = Baik

Bila jenis kelamin Perempuan, waktu luang dalam sehari 4 jam, intensitas penggunaan gadget rendah, maka digolongkan sebagai baik.

15. Jenis Kelamin > Perempuan, 4 jam, sedang, baik = Baik

Bila jenis kelamin Perempuan, waktu luang dalam sehari 4 jam, intensitas penggunaan gadget sedang, maka digolongkan sebagai baik.

16. Jenis Kelamin > Perempuan, 4 jam, tinggi, tidak, baik = Baik

Bila jenis kelamin Perempuan, waktu luang dalam sehari 4 jam, intensitas penggunaan gadget tinggi, tidak mengikuti ekstrakurikuler, maka digolongkan sebagai baik.

17. Jenis Kelamin > Perempuan, 4 jam, tinggi, ya, sangat baik = Sangat Baik

Bila jenis kelamin Perempuan, waktu luang dalam sehari 4 jam, intensitas penggunaan gadget tinggi, mengikuti ekstrakurikuler, maka digolongkan sebagai sangat baik.

18. Jenis Kelamin > Perempuan, Di atas 5 jam, rendah, sangat baik $=$ Sangat Baik

Bila jenis kelamin Perempuan, waktu luang dalam sehari di atas 5 jam, intensitas penggunaan gadget rendah, maka digolongkan sebagai sangat baik.

19. Jenis Kelamin > Perempuan, Di atas 5 jam, sedang, sangat baik = Sangat Baik

Bila jenis kelamin Perempuan, waktu luang dalam sehari di atas 5 jam, intensitas penggunaan gadget sedang, maka digolongkan sebagai sangat baik.

20. Jenis Kelamin > Perempuan, Di atas 5 jam, tinggi, tidak, sangat baik = Sangat Baik

Bila jenis kelamin Perempuan waktu luang dalam sehari di atas 5 jam, intensitas penggunaan gadget tinggi, tidak mengikuti ekstrakurikuler, maka digolongkan sebagai sangat baik.

\section{Jenis Kelamin > Perempuan, Di atas 5 jam, tinggi, ya, baik = Baik}

Bila jenis kelamin Perempuan waktu luang dalam sehari di atas 5 jam, intensitas penggunaan gadget tinggi, mengikuti ekstrakurikuler, maka digolongkan sebagai baik.

Berdasarkan hasil dari pohon keputusan di atas, maka didapati bahwa penggunaan gadget tidak mempengaruhi nilai akhir siswa karena hanya 1 cabang pohon saja yang menunjukkan hasil "Kurang" sedangkan cabang-cabang yang lainnya menunjukkan hasil "Baik" dan "Sangat Baik". 


\section{Kesimpulan}

Berdasarkan penelitian dan pengolahan data yang sudah dilakukan mengenai pengaruh penggunaan gadget di murid SMA secara umum terhadap nilai akhir, maka dapat disimpulkan sebagai berikut:

1. Setelah melakukan penelitian dengan menggunakan metode data mining pada siswa SMA secara umum untuk menganalisa pengaruh penggunaan gadget terhadap nilai akhir siswa SMA secara umum, didapati algoritma data mining id3 menghasilkan tingkat akurasi 49,39\%. Ini menandakan bahwa algoritma ini kurang cocok dalam penelitian ini.

2. Pengaruh penggunaan gadget dengan nilai akhir siswa memiliki dampak yang baik berdasarkan hasil prediksi dari pohon keputusan.

\section{Referensi}

[1] P. Chusna, "PENGARUH MEDIA GADGET PADA PERKEMBANGAN KARAKTER ANAK", Dinamika, vol. 17, no. 2, pp. 315-330, Dec. 2017.

[2] P. Kasih, "Pemodelan Data mining Decision tree Dengan Classification Error Untuk Seleksi Calon Anggota Tim Paduan Suara," Innovation in Research of Informatics (INNOVATICS), vol. 1, no. 2, 2019.

[3] Dez Ozadad Selan, A. A. (2019). PENGARUH PENGGUNAAN GADGET TERHADAP PRESTASI DAN HASIL . Salatiga: Fakultas Teknologi Informasi Universitas Kristen Satya Wacana.

[4] D. W. Nurmalasari, "PENGARUH PENGGUNAAN GADGET TERHADAP TINGKAT PRESTASI," Journal Ilmu Pengetahuan Dan Teknologi Komputer, vol. 3, no. 2, 2018.

[5] Sulastri, H., \& Gufroni, A. I, "Penerapan data mining dalam pengelompokan penderita thalassaemia", Jurnal Nasional Teknologi dan Sistem Informasi, vol. 3, no. 2, 299-305, 2017

[6] Analisa Data mining Untuk Forecast Penjualan pada Cv. Yova Bersaudara Menggunakan Algoritma J48 [Book] / auth. Situmeang Jamal. - 2008.

[7] RAHMAT C.T.I., Brilian et al. IMPLEMETASI K-MEANS CLUSTERING PADA RAPIDMINER UNTUK ANALISIS DAERAH RAWAN KECELAKAAN. Prosiding Seminar Nasional Riset Kuantitatif Terapan, [S.I.], p. 58-62, may 2017.

[8] Khulwia, K. (2018). Pengaruh Penggunaan Gadget Dan Lingkungan Belajar Terhadap Hasil Belajar Siswa Pada Mata Pelajaran IPS Di Kelas VIII SMP Negeri 13 Malang. Malang: Jurusan Ilmu Pengetahuan Sosial Fakultas Ilmu Tarbiyah Dan Keguruan Universitas Islam Negeri Maulana Malik Ibrahim Malang.

[9] Kompas.com, "Agar Mudah Cari Sekolah dan Beasiswa, Ketahui Kriteria Nilai UN 2020," Kompas.com, 9 January 2020. [Online]. Available: https://edukasi.kompas.com/read/2020/01/09/14031931/agarmudah-cari-sekolah-dan-beasiswa-ketahui-kriteria-nilai-un-2020?page=all\#page2. [Accessed 16 April 2021]. 